\title{
Fatos e marcas: das memórias e conquistas do Grupo Com Vida
}

\author{
Denise H. Afonso, ${ }^{1 *}$ Lia Márcia C. da Silveira, ${ }^{2}$ Michael Deveza, ${ }^{1}$ Elizabeth da L. Marques, ${ }^{3}$ Thiago P. \\ Bártholo, ${ }^{4}$ Daniel S. N. Puig ${ }^{1}$
}

\section{Resumo}

Apresentamos a experiência do Grupo Com Vida, a mais consistente e duradoura do trabalho/ensino com grupos do Departamento de Medicina Integral, Familiar e Comunitária da Faculdade de Ciências Médicas da Universidade do Estado do Rio de Janeiro (FCM-UERJ). Iniciamos descrevendo o contexto mundial, nacional e local no momento de construção do grupo, caracterizando as pessoas e suas necessidades à luz da AIDS, do Hospital Universitário Pedro Ernesto e do Ambulatório de Medicina Integral. Seguimos com a constituição do grupo, seus atributos essenciais, organização, referencial teórico de sustentação, características, importância do espaço de reflexão de equipe como parte do processo de educação permanente, suas interfaces e desdobramentos. Destacamos a interdisciplinaridade com a participação de profissionais de diferentes categorias com ênfase na permanência do médico durante os 20 anos de atividades e a necessidade de (re)construção sempre colaborativa. Seguimos com foco na formação de profissionais de saúde, desde a graduação até a residência, médica e de outras áreas da saúde. Resgatamos a experiência do primeiro aluno de Medicina a participar do grupo, sua vivência nas atividades na comunidade, em especial o Memorial das Velas Acesas com foco no processo de ensinagem: o que aprendeu e levou consigo? o que pode nos ensinar? Na continuidade natural da graduação, apresentamos a reflexão de um ex-residente de medicina de família ao participar do grupo, o impacto dessa experiência em sua trajetória profissional, tensões e desafios deste modelo de cuidado. Finalizamos com o valor da grande parceria com os multiplicadores, presentes nas memórias e marcas, caracterizando a importância, ainda hoje, século XXI, do Grupo Com Vida.

Descritores: Educação em saúde; Assitência integral à saúde; Grupos de autoajuda ; HIV; AIDS.

\section{Abstract \\ Facts and marks: the memories and achievements of Com Vida Group}

The article presents the experience of Com Vida Group, the most consistent and longstanding group activity of the Family Medicine Department of the Rio de Janeiro State University. We start by describing the global, national and local context in which the group was created, featuring people and their needs regarding AIDS, Pedro Ernesto University Hospital and the Family Medicine ambulatory. We proceed reporting the group's formation, its special attributes, organization, theoretical framework, characteristics, the importance of a team's deliberation space integrating the permanent education process, its interfaces and developments. The work highlights interdisciplinarity, with the participation of multiple health-
1. Departamento de Medicina Integral, Familiar e Comunitária Faculdade de Ciências Médicas. Universidade do Estado do Rio de Janeiro. Rio de Janeiro, RJ, Brasil.

2. Hospital Escola São Francisco de Assis. Residência Multiprofissional. Universidade Federal do Rio de Janeiro. Rio de Janeiro, RJ, Brasil.

3. Serviço Social. Hospital Universitário Pedro Ernesto. Universidade do Estado do Rio de Janeiro. Rio de Janeiro, RJ, Brasil.

4. Serviço de Pneumologia. Hospital Universitário Pedro Ernesto. Universidade do Estado do Rio de Janeiro. Rio de Janeiro, RJ, Brasil.

*Endereço para correspondência:

Rua Humaitá, 282, bloco 2, apt. 1.703

Rio de Janeiro, RJ. CEP: 22261-004.

E-mail: deniseherdy@gmail.com

Revista HUPE, Rio de Janeiro, 2016;15(3):261-270

doi: $10.12957 /$ rhupe.2016.29471

Recebido em 23/07/2016. Aprovado em 27/10/2016.

care work categories, focusing the participation of the physician during the 20 years of Group activities and the need for collaborative (re)construction. The formation of health care professionals is emphasized, from graduation to residency. The article recovered the experience of the first medical student to join the group, his participation in community activities, especially the Candlelight Memorial: what did he learn? what can he teach us? Along the natural graduation progress, the authors present the outcomes for a former Family Medicine Resident, who took part in the group, what was the impact on his career, and the worries and challenges of this healthcare model. Finally, the article points out the importance of the partnership with people living with HIV, shown in memories and marks that light up the value of Com Vida Group in the 21st century.

Keywords: Health education; Comprehensive health care; Self-help groups; HIV; AIDS.

\section{Resumen}

\section{Hechos y marcas: los recuerdos y logros del Grupo Com Vida}

Se presenta la experiencia del Grupo Com Vida, la actividad del grupo más consistente y de larga data del Departamento de Medicina Familiar de la Universidad del Estado de Río de Janeiro. Comenzamos describiendo el contexto global, nacional y local en el que se creó el grupo, con la gente y sus necesidades a la luz del sida; Hospital Universitario Pedro 


\section{Relato exper}

Ernesto y la Clínica de Medicina Integrativa. Procedemos a informar sobre la formación del grupo, sus atributos especiales, organización, marco teórico, las características, la importancia del espacio de deliberación de un equipo, sus interfaces y desarrollos. Nos centramos en la interdisciplinariedad, con la participación de múltiples categorías de trabajo en salud, destacando la participación del médico durante los 20 años de actividades y la necesidad de (re) construcción colaborativa permanente. Seguimos centrándonos en la formación de los profesionales de la salud, de la licenciatura a la residencia, médicos y otras áreas de salud. Recordamos la experiencia del primer estudiante de medicina para unirse al grupo, su

\section{O início de um novo desafio}

\section{"A doença me trouxe qualidade de vida."}

Estamos em 1990, uma década depois dos primeiros casos de AIDS no mundo. Uma monografia para finalizar uma Especialização em Medicina do Trabalho com o título: "A AIDS e o trabalho: aspectos éticos e sociais" trazia o seguinte texto:

Até o momento estamos diante de uma doença fatal. Como se não bastasse essa dura realidade temos que conviver com a discriminação e o preconceito contra os doentes ou portadores do vírus e com o ódio e arrogância dos, até então, saudáveis. No entanto, dia após dia, a AIDS se aproxima de cada um de nós, bate na porta de cada família brasileira, retira do convívio social homens e mulheres, simples e ilustres, crianças inocentes, amigos, pacientes, seres humanos, enfim. Só há uma saída: o esforço coletivo, fundado na solidariedade com o objetivo fundamental de lutar para que os portadores do vírus, assintomáticos ou doentes, tenham plenos direitos civis, para que possam viver como cidadãos completos, longe da solidão e da clandestinidade. Esta é uma luta de todo povo brasileiro em busca da democracia a fim de que nosso País, já tão repartido socialmente não seja também dividido entre doentes e sãos. ${ }^{1}$

Era o início de uma nova década e a AIDS, incialmente entendida como doença do "Especialista em Infectologia", progressivamente ultrapassava esta barreira transformando-se em enfermidade de atendimento multidisciplinar, requerendo envolvimento dos médicos generalistas, especialistas e profissionais de saúde de diversas áreas, lançando um desafio ao cuidado: a necessidade de integração perfeita entre profissionais e destes com instituições de saúde com objetivo principal participación en actividades de la comunidad, especialmente la Vigilia de Velas Encendidas ¿Qué aprendió? ¿qué puede enseñarnos? Dentro del progreso natural de la graduación, se presentan los resultados de la trayectoria profesional de un antiguo residente de medicina familiar, quien participó en el grupo, las preocupaciones y desafíos de este tipo de atención. Por último, destacamos la importancia de la asociación con personas que viven con el VIH, que se muestran en las memorias y las marcas, que iluminan el valor del Grupo Com Vida, hoy, en el siglo 21 .

Palabras clave: Educación en salud; Atención integral de salud; Grupos de autoayuda; VIH; SIDA.

de promover atenção integral aos indivíduos, tão duramente agredidos pelo adoecimento.

No Hospital Universitário Pedro Ernesto da Universidade do Estado do Rio de Janeiro (HUPE-UERJ), desde 1991, o Serviço de Infectologia, identificando demanda superior à capacidade de atendimento, passou a referir pacientes soropositivos para HIV, necessitando de acompanhamento ambulatorial, ao Ambulatório de Medicina Integral (AMI).

Colocado no centro da epidemia de AIDS, o AMI necessitou de uma reorganização estrutural para oferta de um acompanhamento técnico e humanamente correto, de forma coerente com seus valores, minimizando assim as consequências devastadoras dessa síndrome.

Nasce o Projeto Multidisciplinar Docente de Prevenção e Assistência a Pessoas Vivendo e Convivendo com HIV/AIDS (PVCHA), acompanhados no AMI com a participação inicial da Psicologia Médica e Serviço Social e clara evidência da necessidade de outros profissionais. Estávamos em junho de 1995, reunidos semanalmente e com metas bem definidas:

a) identificar tamanho e perfil da população de PVCHA em acompanhamento no AMI;

b) definir normas de acesso, fluxo de atendimento, investigação, profilaxia e tratamento das doenças relacionadas à AIDS para alinhar condutas;

c) integrar atendimento no AMI com serviços de apoio diagnóstico e terapêutico, facilitando contato com outros serviços da rede pública e inserção no sistema de Referência e Contrarreferência;

d) organizar as atividades das áreas de saúde envolvidas no cuidado às PVCHA;

e) iniciar grupo reflexivo, multidisciplinar, com participação de PVCHA acompanhadas no AMI para discutir, esclarecer dúvidas, oferecer suporte ao acompanhamento médico;

f) incrementar desenvolvimento de pesquisas clínicas 
e comportamentais direcionadas a PVCHA, seus familiares e parceiros.

Em 3 de julho de 1996 aconteceu a primeira reunião do Grupo Com Vida com a participação de assistente social, médica, psicóloga e seis PVCHA. Completamos duas décadas de existência com muitas memórias e conquistas, atividades grupais sem interrupção, chegada de alunos e pós-graduandos de diferentes cursos da UERJ e outras instituições, produção científica, atividades comunitárias, formação de multiplicadores, criação de Centro de Treinamento em Aconselhamento, premiação em editais públicos e outros concursos e muito aprendizado.

Vamos compartilhar essa trajetória em relatos dos profissionais de saúde dedicados e envolvidos com o Grupo Com Vida e trazer breves narrativas de seus participantes.

\section{Construção do grupo: pessoas e suas necessidades}

"Aprendi que a gente não vai morrer assim... começamos outra vida e a casa aqui (meu corpo) tem dono, e sou eu, não esse vírus."

O ano de 1996 foi um divisor de águas no tratamento de PVCHA. Alguns anos depois do surgimento de novas opções terapêuticas, foi possível comprovar que a associação de medicamentos de alta potência foi decisiva para os rumos do cuidado, a redução da mortalidade geral e da transmissão do HIV.

No Brasil, a epidemia ainda estava em fase de crescimento com escalada entre mulheres, pobres e homens que fazem sexo com homens (HSH). A partir dos grandes centros ela se interiorizou. Seguia os passos de outros países e continentes onde já era prevalente. ${ }^{2} \mathrm{~A}$ transmissão heterossexual tornava-se uma evidência e a noção de vulnerabilidade deixava o campo exclusivo dos chamados "grupos de risco" para se tornar um alerta a todos. Foram desenvolvidas estratégias de prevenção diversificadas, tais como estímulo ao uso de preservativos em todas as relações, redução do número de parceiros, testagem voluntária, controle de bancos de sangue, redução de danos relacionados às drogas etc. Contudo, os ganhos e as restrições no campo da saúde ainda suscitam polêmicas acerca de sua efetividade.

Na conferência da International AIDS Society 2005, no Rio de Janeiro, Marie Laga ${ }^{3}$ afirmou: "se não integrarmos as medidas de prevenção e tratamento, essa epidemia vai aumentar". Tal como um mosaico epidêmico, foi exatamente o que aconteceu e prossegue acontecendo.
Em nosso meio, há aumento da incidência entre jovens, mulheres acima da quarta década de vida e entre HSH. Mais ainda: transformou-se numa epidemia partida. De um lado, pessoas sem acesso aos medicamentos; de outro, pacientes recém-infectados com alta capacidade de transmissão por elevada carga viral. Uma epidemia de contrastes: ao examinarmos homens e mulheres negros verificamos maior incidência em comparação com brancos, em países desenvolvidos como Estados Unidos. A despeito das estratégias de prevenção, uma permanece desde sempre com alta capacidade de redução de casos novos: uso adequado e sistemático de preservativos. ${ }^{4}$ A partir de 1988, segundo o Banco Mundial, ${ }^{5}$ foram fornecidos mais de US\$ 2,7 bilhões em doações e empréstimos, uma das principais fontes de financiamento para combate ao HIV/AIDS no mundo.O Programa Multinacional HIV/AIDS (MAP) para a África investiu US\$ 1,2 bilhões para ajudar países a expandir seus programas de prevenção, cuidados e tratamento. Diversos projetos, na Índia e no Brasil, estabeleceram organismos responsáveis pelo HIV/AIDS e conhecimentos especializados, comprometeram organizações não governamentais na prevenção e cuidados, criaram conscientização pública e estimularam debate político. $\mathrm{O}$ investimento do Brasil na prevenção e tratamento manteve a incidência de HIV abaixo de $1 \%$ e reduziu à metade as mortes relacionadas a AIDS.

Além dessas estratégias, acompanhamos a criação de espaços multiprofissionais de acolhimento, aconselhamento e informação que pudessem modificar comportamentos e identificar vulnerabilidades. No HUPE, profissionais e pacientes consolidaram um espaço de discussão de situações concretas e compartilhamento de experiências denominado Grupo Com Vida.

O Com Vida, vinculado ao Departamento de Medicina Integral Familiar e Comunitária (DMIFC) da Faculdade de Ciências Médicas (FCM) da UERJ, é um espaço de reconstrução de práticas e desenvolvimento docente-assistencial, especialmente de médicos. Atividades semelhantes com proposta grupal, tradicionalmente, têm sido lideradas por profissionais não médicos, pois na formação de médicos atividades multiprofissionais e interdisciplinares sempre estão em segundo plano.

Em decorrência desta lacuna de formação, o clínico não está plenamente capacitado para suas atividades profissionais por conta da orientação pedagógico-educacional excessivamente simplificadora e estritamente vinculada a uma concepção mecanicista dos complexos fenômenos biopsicossociais que circunscrevem o adoecimento humano. A integração dos profissionais de saúde 
no âmbito das atividades grupais é fundamental para aprimorarmos conceitos de vínculo, escuta, acolhimento e percepção ampliada do cuidado. Ao nos inclinarmos sobre aqueles que em nós depositam expectativas e esperanças, percebemos que tecnologias integrais contribuem para refazermos caminhos de mão dupla entre quem precisa e quem oferece cuidado. Perceber e aprender com o saber do outro contribui para ressignificação dos conceitos de resiliência, autonomia e protagonismo, possibilitando intervir nas situações de risco e vulnerabilidade das pessoas, famílias e comunidades.

Os fenômenos que circunscrevem o adoecimento humano são dinâmicos e se reportam às narrativas das pessoas e sua natureza envolve sentidos e significados numa rede de eventos interdisciplinares. O espaço para desenvolvimento de saberes é o encontro de cuidadores e pessoas de que cuidamos.

O Com Vida surgiu, nesta perspectiva, enquanto espaço terapêutico, de encontro, para que pudéssemos desafiar a epidemia de HIV/AIDS. Lá aprendemos a escutar antes de falar, incluir quando muitos estavam esquecidos à margem, a nos perceber solidários à dor de ser solitário. Aprendemos a ouvir para entender as dúvidas além da reprodução do conhecimento biomédico subjacente. Um trabalho integral, coletivo e um novo espaço terapêutico expresso na releitura do símbolo mundial da AIDS (Figura 1).

\section{Sentidos e significados do Grupo Com Vida}

"Eu encontrei profissionais de saúde que trocam comigo. Eu não sei quem tem o vírus: eu ou eles."

O Brasil foi o primeiro país em desenvolvimento a adotar políticas públicas de acesso a tratamento antirretroviral. Das diretrizes que norteiam essa política, ${ }^{6}$ enfatizamos a garantia da cidadania e direitos das PVCHA, do acesso aos insumos de prevenção para todos, direito ao diagnóstico e acesso universal e gratuito aos recursos disponíveis para tratamento. Desde sua implantação, ele se norteia pelo princípio da integralidade do cuidado constituinte do Sistema Único de Saúde (SUS), associando sociedade civil e Estado.

Neste contexto, iniciam-se as atividades do Com Vida, formado por profissionais de saúde e PVCHA em acompanhamento no HUPE. Seus objetivos, rotina e constituição estão expressos no convite para as atividades (Figura 2).

Os princípios organizadores deste trabalho grupal incluem os itens a seguir.

\section{Atenção integral}

A contribuição do modelo de atenção baseado no princípio da integralidade vem do entendimento do homem biopsicossocial, que se estrutura como sujeito pela estreita relação e interação das diversas dimensões que o constituem. Esta compreensão dá margem ao entendimento do processo saúde-doença que recusa o reducionismo e ultrapassa o biológico, incidindo sobre práticas dos profissionais de saúde como um princípio orientador que considera o indivíduo em sua totalidade, influenciando seu modo de cuidar, com foco na pessoa e não na doença. Promove uma assistência além

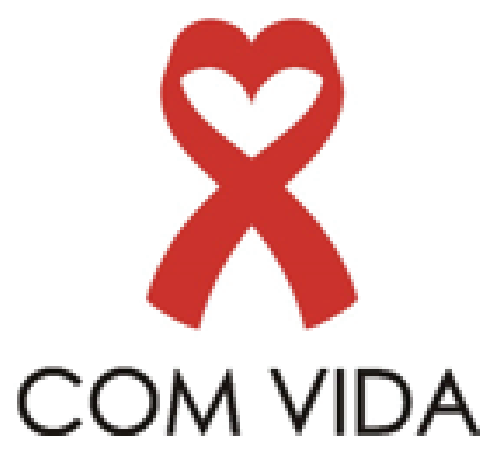

Figura 1. Logomarca do Grupo Com Vida elaborada em comemoração aos 10 anos do Grupo, pela designer Thais Cruz, em 2006

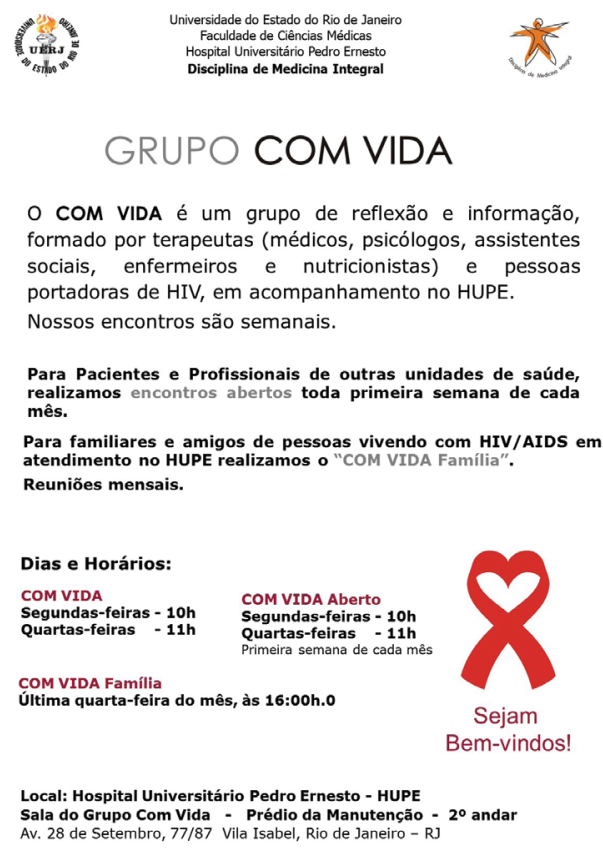

Figura 2. Convite - período 2002-2006 
da doença e do sofrimento manifesto incluindo no cuidado às pessoas, suas necessidades mais abrangentes.

O princípio da integralidade é um dos pilares estruturantes das ações do Com Vida, pois permite o conhecimento recíproco e abre caminho para o diálogo, por meio do qual se constrói uma relação interpessoal que "descoisifica" sujeitos, percebe diversidades, cria vínculos, compreende as necessidades de quem sofre e influencia o processo de trabalho e as ações de saúde.

No Com Vida, além dos objetivos relacionados ao cuidado em saúde em sentido estrito, visamos colaborar com as PVCHA a lidar com o impacto do diagnóstico, o preconceito, a segregação social, facilitando a criação de uma rede de suporte social. ${ }^{8}$

\section{Concepção pedagógica problematizadora}

Esse processo coletivo e interativo de pessoas e conhecimentos apoia-se no método dialógico, participativo, permitindo aos sujeitos envolvidos mergulharem na vida e desvelarem as reais dificuldades no processo de aderir ao tratamento. Esta forma de atuar busca sustentação na Pedagogia, fundamentando-se no método de Paulo Freire, para orientar o procedimento na ação com base no respeito ao outro, na conquista da autonomia e na dialogicidade.

No Com Vida experimentamos uma prática baseada no diálogo, que prioriza o homem e valoriza a potencialidade humana, permite entrar em contato com outros modos de pensar e viver a vida e traz para o cotidiano dos serviços de saúde a possibilidade de discutir problemas importantes que estejam dificultando o cuidado.

Informação e comunicação são centradas no sujeito que busca o cuidado. O diálogo se dá a partir do conhecimento prévio das pessoas, e a função do profissional de saúde é ser facilitador, mediador e problematizador das questões que emergem no grupo compromissado com a reflexão e a crítica. ${ }^{9}$

\section{Grupo operativo}

Da ciência da Psicologia vem a contribuição que caracteriza o Com Vida como prática coletiva, em uma estrutura na qual pessoas se aproximam, vinculam e interagem, estabelecendo uma relação dialógica favorecedora da integração do conhecimento intelectual com a vivência e facilitando a transformação da atitude frente ao cuidado com a saúde. Esta prática assistencial terapêutica amplia a consciência sobre a doença, potencializa a capacidade humana de superar dificuldades e propicia aprendizagem mútua e recíproca, pois ao trabalhar uma determinada situação não é só esta situação que se modifica, mas também o sujeito que, transformado, contribui para modificar a situação. Há, portanto, uma bilateralidade no processo: o sujeito afeta e é afetado, evidenciando que ensino e aprendizagem são "passos dialéticos e inseparáveis, integrantes de um processo único em permanente movimento". ${ }^{10}$

Os integrantes do grupo, por meio de um disparador trazido para discussão, problematizam questões relacionadas às necessidades de saúde de forma geral, colocando frente a frente pacientes e profissionais, tendo como meta ser um processo de desenvolvimento de pessoas para transformar a realidade. Dialoga-se sobre a compreensão do processo saúde-doença, dificuldades e estratégias para aderir ao tratamento, evolução terapêutica, direitos e deveres dos cidadãos em relação ao cuidado e ao sistema de saúde, relação profissional de saúde paciente, autonomia e participação no tratamento e cuidado com a vida, presente na ação circulante do espaço grupal.

\section{Educação permanente}

Definido como espaço de reflexão da equipe visando à compreensão do processo de trabalho e da dinâmica grupal no qual estão envolvidos. Trata-se de um processo contínuo (pré e pós-atividade) que busca aplicabilidade prática e significado nas experiências vivenciadas, sua relação com a realidade e sua potência transformadora.

Neste espaço reflete-se sobre construção coletiva e interação, comunicação, criatividade, conflitos intraequipe e na relação com o grupo, promoção da autonomia, construção da interdisciplinaridade nas ações de saúde, entre outros assuntos.

É momento também de refletir sobre dinâmica grupal e incorporá-la como tecnologia de cuidado à saúde, planejar o agir em saúde de modo interativo e complementar em dinâmica multidisciplinar, ampliar ideias sobre modelo biomédico e cuidado com a vida, visando desenvolver ações de proteção, promoção da saúde e prevenção de agravos.

Considerando os princípios orientadores do trabalho realizado no Com Vida, cabe destacar os aspectos relevantes relacionados ao Grupo: facilitador e técnica.

\section{O grupo}

"Nós somos sempre vulneráveis! Entre pessoas como nós, nós nos sentimos bem." 


\section{Relato exper}

Na proposta do Com Vida a demanda nasce do próprio grupo. Todo grupo possui um saber e a troca entre os componentes possibilita emersão de conhecimentos e, na construção de saber, o grupo pode encontrar respostas para suas questões.

\section{O facilitador}

"Não acredito em qualquer coisa, acredito em quem cuida de mim."

Espera-se que tenha postura clarificadora, de suporte, motivadora, não impositiva, conhecimento dos temas, potencial criativo para lidar com o inesperado, flexibilidade para integrar contribuições que enriqueçam ou complementem seu trabalho sem perder de vista o foco no cuidado.

\section{A técnica}

"Aqui é um porto, a gente se abastece e vai embora."

Leva em consideração o objetivo do grupo sendo fundamentada em metodologia interativa, dialógica, não interpretativa, com informações contextualizadas e valorização das experiências trazidas.

A complexidade desta prática grupal traz alguns desafios ao seu desenvolvimento e sustentabilidade. Podemos destacar obstáculos institucionais, desde espaço físico inexistente ou inadequado a uma reunião circular até a (in)compreensão desta prática como terapêutica e não meramente uma conversa recreacional.

Outro desafio é identificar novos indicadores qualitativos de promoção de mudanças na saúde a partir da atenção integral, tais como qualidade da adesão ao tratamento e grau de satisfação com a vida.

Há também o desafio da construção da cultura de trabalho coletivo, multidisciplinar, visando interdisciplinaridade das ações de saúde. Embora as Diretrizes Nacionais para Formação em Saúde orientem para exercício da interprofissionalidade, o modelo de formação é, predominantemente, uniprofissional, privilegiando experiências de aprendizagem individualizadas e individualistas.

\section{Um grupo construído na interface das profissões e do cuidado}

"Esse vírus é nosso! A AIDS hoje ainda não tem cura,
tem controle. E a vida é uma escolha."

O SUS completou duas décadas e um dos seus desa- fios é a mudança da consciência sanitária de gestores, profissionais de saúde e usuários. Essa é uma tarefa de grande monta, considerando a lógica biologicista que ainda vigora nos corações e mentes daqueles que fazem a política de saúde acontecer em nosso país.

Em relação ao processo coletivo do trabalho na saúde, é patente o despreparo e/ou desinteresse dos profissionais de saúde em organizar práticas integradas, que oportunizariam um impacto sociossanitário maior na vida das pessoas.

Em seu artigo É possível construir novas práticas assistenciais no Hospital Público?,11 Adail de Almeida Rollo cita quatro "nós" a serem enfrentados para uma resposta positiva; destacaremos três destes:

- Responsabilização e vínculo - o autor aborda a impessoalidade e fragmentação da assistência e chama atenção para supervalorização dos procedimentos como um fim em si mesmos.

- O doente como cidadão, sujeito em seu processo de recuperação e cura - ele indaga até quando os usuários serão tratados como objetos de interesse científico dos profissionais de saúde, na perspectiva do autoritarismo e prepotência daqueles que, supostamente, "sabem".

- Resolutividade da atenção - enfatiza que o hospital público deveria ampliar seu papel na garantia da equidade do acesso e de uma assistência resolutiva.

Aprendemos que o enfrentamento desses "nós" passa pela crítica à forma como organizamos nosso processo de trabalho, historicamente caracterizado pelo individualismo e competição, em detrimento da construção de práticas multi/interdisciplinares.

A interface entre práticas educativas e interdisciplinaridade configura-se uma conexão importante para construção da integralidade no cotidiano da assistência à saúde. Considerada como tecnologia leve por Merhy,11 a dinâmica grupal conduzida no eixo da interdisciplinaridade requer dos profissionais preparo teórico, político, pedagógico e relacional.

De acordo com Assis, ${ }^{12}$ e reforçando os pressupostos do Com Vida, os princípios teórico-metodológicos que devem orientar práticas na educação em saúde têm raízes, como já destacamos, nas concepções pedagógicas de Paulo Freire e podem ser identificados como: compreensão de saúde como qualidade de vida, educação como processo formativo do humano, opção filosófico-política pela não opressão, reconhecimento e interação com cultura popular, adoção de metodolo- 
gias participativas, estímulo aos processos dialógicos e reflexivos e prática voltada à afirmação dos sujeitos e valorização da afetividade.

Gomes e Bakita ${ }^{13}$ ressaltam que a complexidade das questões de saúde requer inovações que propiciem interação com usuários na busca de alternativas e soluções individuais e coletivas para demandas apresentadas, correlacionado estas questões a um conjunto de fatores sociais, econômicos, políticos, históricos e culturais que interagem e são reiterados no cotidiano dos serviços de saúde.

Em relação ao conceito das interdisciplinaridades, Minayo $^{14}$ destaca que este conceito surgiu no século XX e, só a partir da década de 60 , começou a ser enfatizado como necessidade de transcender e atravessar o conhecimento fragmentado, embora sempre tenha existido, em maior ou menor medida, uma certa aspiração à unidade do saber.

Pensar o grupo como ferramenta de trabalho coletivo oportuniza pensarmos no potencial de mudanças institucionais que se consolidaram no HUPE a partir do ganho crescente de autonomia de usuários e profissionais, articulados numa trama cooperativa, que passam a interferir nas dinâmicas por vezes tão cristalizadas ao nosso redor institucional.

O Com Vida acolheu em sua trajetória histórica profissionais de diferentes disciplinas/departamentos/ áreas, com destaque para médicos, todos vinculados ao DMIFC, enfermagem, nutrição, psicologia e serviço social. Essa composição oportunizou compreensão ampliada das questões trazidas pelos usuários, conhecimento entre as profissões e sobre as peculiaridades de outras disciplinas e saberes.

A frase que explicita o exercício da interdisciplinaridade nas reuniões do Com Vida é regularmente repetida por um profissional referindo-se à intervenção do colega e dizendo: "Hei, essa fala é minha...". Sem o caráter de onipotência e hierarquia, reconhece em ato, o aprendizado do outro profissional que compreende e se apropria dos saberes ali compartilhados, ampliando suas competências e a resolutividade do cuidado.

No Com Vida todos os envolvidos na dinâmica grupal saem lucrando: usuários aprendem a articular suas experiências na perspectiva da totalidade; residentes e estagiários experimentam uma intervenção-formação adequada às exigências da sociedade multifacetada e complexa; profissionais alargam suas competências individuais e coletivas, configurando um trabalho educativo que impacta a vida de todos que participam dessa experiência.
A construção da interdisciplinaridade não prescinde, assim, da disciplinaridade; antes, exige que sejamos competentes em nossas áreas profissionais, para que, no coletivo, possamos construir novos saberes e novas competências sem medo de nos perdermos nesse processo.

\section{Tempo de aprender e ensinar: da graduação à residência, sementes e frutos}

\section{Texto-narrativa 1}

"Tudo que eu sei, aprendi aqui. Todo dia aprendo alguma coisa."

Grupo Com Vida? Essa foi a primeira pergunta que eu, Thiago Prudente Bártholo, me fiz quando iniciei no projeto de extensão em 2002.

Nunca havia usado um estetoscópio, nem sabia aferir pressão arterial. Estava "apenas" no terceiro período (segundo ano) quando me vi diante de uma realidade diferente daquilo que eu imaginava ser a medicina. Caí literalmente de paraquedas em um grupo de PVCHA e, na expectativa dos pacientes, chegava com um suposto saber de profissional de saúde.

O médico ésempre prepotente desde sua aprovação no vestibular e eu, em primeira análise, estava certo que tinha muito a ensinar àquelas pessoas e, diante de alguma dúvida, se consultasse os livros de clínica médica do meu pai, também médico, tudo seria muito fácil. Tiraria de letra.

Entretanto, logo na primeira reunião percebi a riqueza daquelas falas e experiências contadas de forma simples e com tantos sentimentos e emoções envolvidas.

A parte médica tradicional - livro, artigo científico, capítulo de AIDS do Harrison - caiu por terra. Não havia nenhum livro médico que descrevesse aquilo que eu presenciava. Reuniões semanais associadas a eventos extramuros do HUPE, como o Memorial das Velas Acesas em 2002 e 2003, eram exemplos vivos de demonstração da força e poder terapêutico daquele grupo, com todas aquelas pessoas, objetivando ajuda mútua e uma vida melhor.

Logo no início engoli a prepotência e percebi que tinha muito mais a aprender do que ensinar e com o tempo entendi que profissional de saúde tem de saber ouvir o paciente, sorrir para o paciente e dar-lhe a mão quando preciso; e isso não tem nada de errado. Não seremos piores médicos por isso, pelo contrário, quando 
esquecermos a soberba, seremos muito melhores.

Hoje, depois de 14 anos, me tornei um médico com especialidade em pneumologia e treinamento em ausculta pulmonar, laudo de exames e elaboração de projetos de pesquisa quantitativos. Entretanto, nunca esqueci a importância de tratar com carinho e ouvir que, muitas vezes, a asma foi desencadeada após tiroteio ou ao presenciar o filho usando droga; que o tabagismo se iniciou após violência domiciliar ou perda de ente querido. Ou seja, aprendi lá atrás com todos aqueles pacientes, que com o tempo se tornaram meus amigos, que a pessoa é uma pessoa e, no caso da minha especialidade, não apenas um pulmão que respira.

Fazer respirar com remédio é fundamental, mas aprender a fazer respirar com palavras é uma mágica Com Vida que tento utilizar todos os dias na minha prática. Não tenho dúvida que, para o aluno de medicina, viver uma experiência como essa faz toda diferença em sua formação. As novas diretrizes da educação médica devem incorporar essas práticas ao currículo. Teremos, com certeza, médicos melhores que irão utilizar o ouvido para auscultar e escutar seus pacientes.

\section{Texto-narrativa 2}

"A gente encontra aqui uma família, e uma das melhores."

Durante a residência em medicina de família e comunidade (MFC) no HUPE, o contato com atividade de grupo compõe parte fundamental da formação, sendo oferecida aos residentes a participação em grupos terapêuticos, entre eles o Com Vida.

A mudança terapêutica, processo bastante complexo - que, por aglutinação semântica em arriscada tentativa de apreensão para a finalidade deste texto, poderíamos definir como "serviço, atendimento, tratamento, cura (do grego therapeía)" - só é possível a partir de interações entre experiências humanas intricadas. Essas experiências Yalom e Leszcz ${ }^{15}$ nomeiam de "fatores terapêuticos". São constructos arbitrários e sua interdependência deve ser considerada, a despeito das descrições em separado que faremos adiante, uma vez que nenhum deles atua isoladamente, como também há de se levar em conta que "os relatos dos pacientes são uma fonte rica e relativamente intocada de informações", sendo tão mais lúcidos e significativos quanto mais profundamente se consegue penetrar no seu mundo de experiências.

Nesse contexto de formação em MFC, quando se tencionam paradigmas e se propõem diálogos entre racionalidades médicas com fortes consequências para a mudança de modelo assistencial, o contato com o Com Vida e o mergulho no universo de experiências, sentimentos e representações das pessoas que o frequentam é uma oportunidade inestimável de transformação pessoal e profissional. Ali observamos, à luz da sistematização proposta por Yalom e Leszcz, coexistirem em dinâmica espontânea:

a) compartilhamento de informações objetivas e pragmáticas, como acesso a direitos de PVCHA até sofisticadas explicações sobre mecanismos de ação dos antirretrovirais disponíveis para tratamento;

b) recapitulação corretiva do grupo familiar primário, compreendida como possibilidade de experimentar, de maneira mais adequada, esses padrões e experiências a partir das interações estabelecidas entre os membros do grupo - talvez uma travessia da fronteira do grupo operativo em direção a um dispositivo de psicoterapia de grupo com desdobramentos decisivos para a vida das pessoas ali presentes e para suas relações familiares originais;

c) desenvolvimento de técnicas de socialização através de ligações mais íntimas, honestas e diretas, permitindo também aprendizagem interpessoal precedida de comportamento imitativo - todos estágios possíveis no espectro entre o isolamento experimentado por ocasião do diagnóstico e sua elaboração (nunca definitiva na medida em que experiências humanas e sentimentos que delas advêm se sucedem initerruptamente);

d) coesão grupal que engendra desde catarse reflexiva até o contato com fatores existenciais - contingências da condição humana e acesso a conteúdos ameaçadores, como morte, liberdade, falta de significado, reatribuições de sentido;

e) e, finalmente, o fator denominado altruísmo, possivelmente a expressão máxima de que nas atividades de grupo - e o Com Vida, em particular, o demonstra - cenário, pessoas, ambiente de colaboração se constituem de maneira tal que o compartilhamento de algo de si mesmo com outros produz um sentimento de utilidade e relevância.

Tal é a expressão do cuidado. E ali as pessoas vivendo e convivendo com HIV/AIDS, somente pessoas, percebem-se cuidadoras de si. E do outro. Para nós, que nos dedicamos ao trabalho em saúde sob esse paradigma, os ganhos desse encontro são absolutamente transformadores. Nele, somos atualizados sobre cuidado na contramão do trabalho mecanizado e impessoal que tantas 
vezes caracteriza nosso fazer de profissionais de saúde.

O grande desafio de combinar trabalho e cuidado reside em uma atitude de retorno ao modo-de-ser-docuidado a que Boff, ${ }^{17}$ em alusão à obra filosófica de Heidegger, se reporta e que implica entender tratar-se de relação sujeito-sujeito, interação mais que intervenção; respeitar, estar em sintonia com coisas e pessoas, chamando a funcionar, não a razão analítico-instrumental que marca o modo-de-ser-do-trabalho, mas o esprit de finesse ("o espírito da delicadeza"), o pathos - mais que o logos - ocupando a centralidade dos encontros, que deveriam ser a grande celebração dos grupos, na medicina (e saúde) de família ou em qualquer ambiente.

\section{Tecnologia do cuidado, a conclusão do aprendizado}

\section{"Eu nunca imaginei que iria crescer tanto a ponto de querer dividir a minha realidade."}

No resgate de memórias e lições aprendidas nestas duas décadas de adesão à vida, ${ }^{18}$ finalizamos com uma linha do tempo (Figura 3), que expressa a trajetória do grupo e outra frase de um participante - "Um dia serei eu a ser lembrado aqui" -, caracterizando a dimensão da transcendência do Com Vida, como define Leonardo Boff: 18 "capacidade de romper todos os limites, superar e violar os interditos, projetar-se sempre num mais além".
A experiência no Com Vida nos ensina a proximidade entre se saber soropositivo para o HIV e ter saúde. Aparentemente paradoxal, é fruto de uma tecnologia de cuidado integral que nos permite ouvir com olhos, pele, coração e ouvidos e agir tendo como objetivo o respeito aos direitos humanos e à promoção da saúde.

\section{Referências}

1. Afonso DH. A AIDS e o trabalho: aspectos éticos e sociais. Monografia apresentada ao Departamento de Medicina Socia e Preventiva da Universidade Gama Filho como requisito parcial do Curso de Especialização em Medicina do Trabalho. RJ, dezembro 1990.

2. Programa Nacional de DST e AIDS: história da AIDS. Disponível em http://www.aids.gov.br/pagina/2010/257 . Acesso em: 22/05/2017.

3. Bertozzi SM, Laga M, Bautista-Arredondo S, Coutinho A. Making HIV prevention programmes work. Lancet. 2008 Sep 6;372(9641):831-44.

4. Laga M, Alary M, Nzila N, et al. Condom promotion, sexually transmitted diseases treatment, and declining incidence of HIV-1 infection in female Zairian sex workers. Lancet. 1994;344(8917):246-8.

5. Programa Global de hiv e AIDS: 10 Fatos sobre hiv e AIDS e o Banco Mundial. Disponível em: http://siteresources.worldbank. org/BRAZILINPOREXTN/Resources/3817166-1185895645304/ AIDSPort.pdf. Acesso em: 22/05/2017.

6. Programa Nacional de DST e AIDS: Direitos humanos e HIV/ AIDS-Avanços e perspectivas para o enfrentamento da epidemia no Brasil. 2008. Brasília, DF. Disponível em: http:// www.aids.gov.br/sites/default/files/DIREITOS_HUMANOS.pdf.
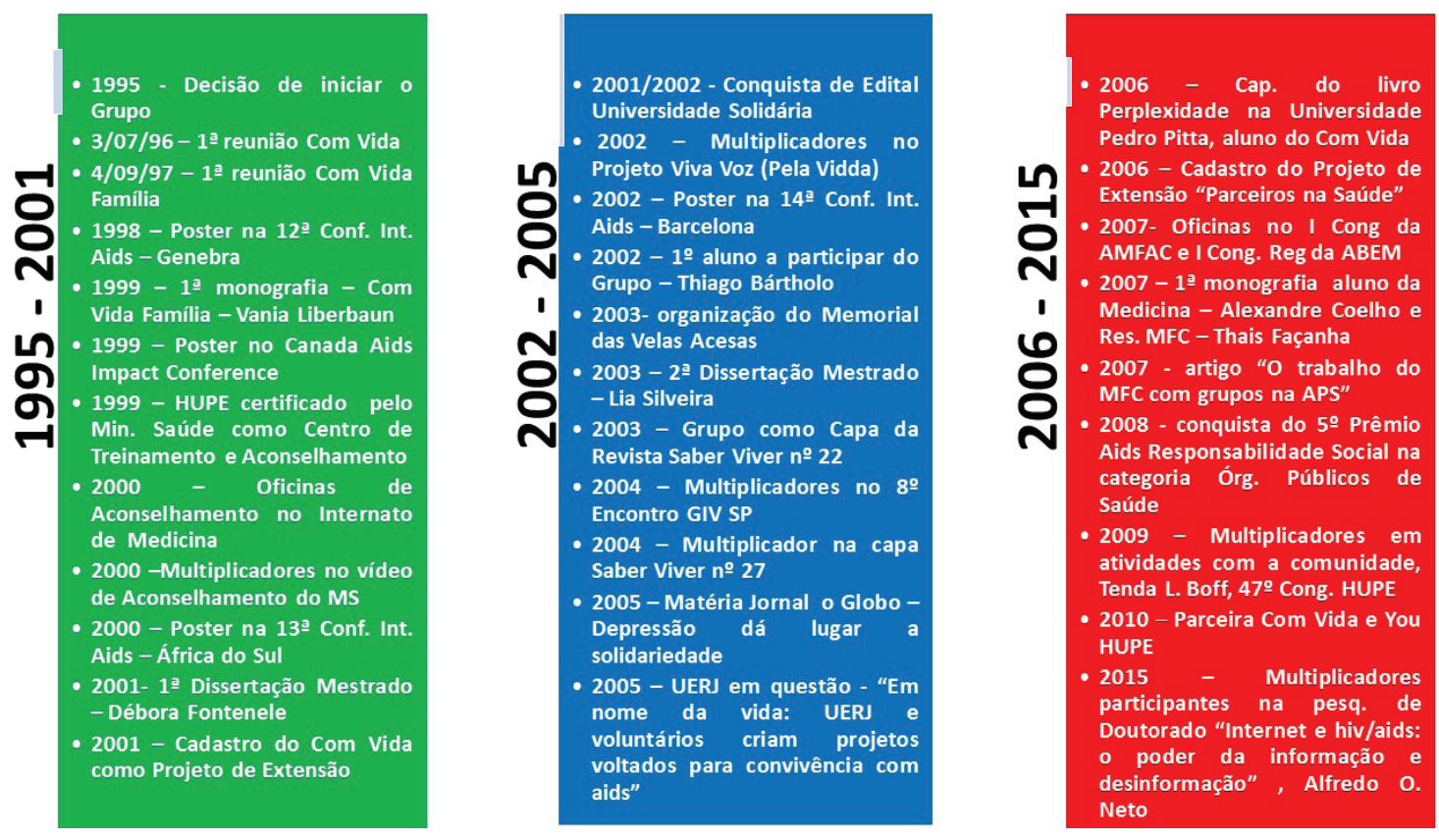

Figura 3. Linha do tempo dos fatos e marcas do Grupo Com Vida 


\section{Relato exper}

Acesso em: 22/05/2017

7. Gomez A. Com Vida e diferente. Saber Viver. 2003; 3(22):12-14. Disponível em: http://saberviver.org.br/publicacoes/com-vida-e-diferente/. Acesso em: 22/05/2017.

8. Silveira LMC, Ribeiro VMB. Grupo de adesão ao tratamento: espaço de "ensinagem" para profissionais de saúde e pacientes. Interface - Comunicação, Saúde, Educação. 2005;9:91-104.

9. Afonso DH, Silveira LMC. O trabalho do médico de família e comunidade com grupos em atenção primária à saúde. In: PROMEF. Porto Alegre: Artmed Editora; 2007. p.49-78.

10. Bleger J. Temas de Psicologia: entrevista e grupos. São Paulo: Cortez; 1989.

11. Rollo AA, Oliveira R.C. É possível construir novas práticas assistenciais no hospital público? In: Merhy EE e cols. Agir em Saúde: Um desafio para o público. 3a ed. São Paulo, SP: Editora Hucitec; 2007. p.321-352.

12. Assis M. Promoção da Saúde e Educação Popular em Saúde: Interface possível e necessária. Jornal Nós da rede: boletim da
Rede de Educação Popular em Saúde. 2003;(5).

13. Gomes SE, Bakita VSC. Grupo com Gestantes numa Unidade de Saúde da Família: Uma experiência interdisciplinar. Trabalho de Conclusão de Curso de Especialização em Saúde da Família, apresentado como requisito para obtenção do título de especialista. Escola Nacional de Saúde Pública, Fundação Oswaldo Cruz; 2007.

14. Minayo MCS. Interdisciplinaridade: uma questão que atravessa o saber, o poder e o mundo vivido. Medicina Ribeirão Preto 1991. abr/jun; 24(2):70-7.

15. Yalom ID, Leszcz M. Psicoterapia de grupo - Teoria e prática; tradução Ronaldo Cataldo Costa. Porto Alegre: Artmed, 2006.

16. Boff L. O Cuidado essencial: princípio de um novo ethos. O cuidado essencial: princípio de um novo ethos. Revista Inclusão Social. 2005;1(1):28-35.

17. Boff L. Tempo de transcendência. Sextante. Rio de Janeiro; 2000.

18. Afonso DH, Silveira LMC. Grupo Com Vida: duas décadas de adesão à vida. São Paulo/Ribeirão Preto: FUNPEC Editora; 2016. p.137-151. 